\title{
Long-Term Remission of Primary Bone Marrow Diffuse Large B-Cell Lymphoma Treated with High-Dose Chemotherapy Rescued by In Vivo Rituximab-Purged Autologous Stem Cells
}

\author{
Hiroshi Kazama, ${ }^{1}$ Masanao Teramura, ${ }^{1}$ Kentaro Yoshinaga, ${ }^{1}$ \\ Akihiro Masuda, ${ }^{2}$ and Toshiko Motoji ${ }^{1}$ \\ ${ }^{1}$ Department of Hematology, Tokyo Women's Medical University, 8-1, Kawada-cho, Shinjuku-ku, Tokyo 162-8666, Japan \\ ${ }^{2}$ Department of Surgical Pathology, Tokyo Women's Medical University, 8-1, Kawada-cho, Shinjuku-ku, Tokyo 162-8666, Japan \\ Correspondence should be addressed to Hiroshi Kazama, kazama@dh.twmu.ac.jp
}

Received 24 July 2012; Revised 11 September 2012; Accepted 25 September 2012

Academic Editor: Robert Peter Gale

Copyright ( $) 2012$ Hiroshi Kazama et al. This is an open access article distributed under the Creative Commons Attribution License, which permits unrestricted use, distribution, and reproduction in any medium, provided the original work is properly cited.

\begin{abstract}
Primary bone marrow diffuse large B-cell lymphoma (DLBCL) is a rare type of extranodal lymphoma with poor prognosis. Here, we report a case of primary bone marrow DLBCL successfully treated with high-dose chemotherapy and rescued by in vivo rituximab-purged autologous stem cells. A 39-year-old woman visited our hospital because of anemia. Bone marrow examination revealed a large B-cell lymphoma invasion. An ${ }^{18} \mathrm{~F}$-fluorodeoxyglucose positron emission tomography scan revealed disseminated bone marrow uptake without evidence of dissemination at other sites. These findings led to a diagnosis of primary bone marrow DLBCL. Our patient underwent R-CHOP (rituximab, cyclophosphamide, doxorubicin, vincristine, and prednisolone) chemotherapy and achieved complete remission. Subsequently, she received high-dose chemotherapy with an in vivo rituximabpurged autologous stem cell transplant. Seven years have passed since the transplantation, and she remains in remission. This suggests that transplantation of an in vivo rituximab-purged autograft is a promising strategy for primary bone marrow DLBCL.
\end{abstract}

\section{Introduction}

The involvement of bone marrow in diffuse large B-cell lymphoma (DLBCL) usually represents the systemic dissemination of lymphoma. However, a rare type of DLBCL involving the bone marrow alone, known as primary bone marrow DLBCL, has been reported [1-3]. The prognosis of primary bone marrow DLBCL is poor with a median survival of 14.9 months, and approximately $70 \%$ of patients die within 2 years despite receiving chemotherapy [4].

High-dose chemotherapy with autologous hematopoietic stem cell rescue is an effective treatment strategy for high-risk non-Hodgkin lymphoma $[5,6]$. Furthermore, treatment with rituximab in addition to stem cell mobilization or a conditioning regimen has been reported to improve the outcome in patients with high-risk B-cell lymphoma [7]. High-dose chemotherapy rescued by in vivo rituximabpurged autologous stem cells is a reasonable approach for primary bone marrow DLBCL because the risk of lymphoma cells being contaminated in the autograft is high. Here, we present a case of a patient with primary bone marrow DLBCL who achieved long-term remission (at least 7 years) after high-dose chemotherapy rescued by in vivo rituximabpurged autologous stem cells.

The present case suggests that this strategy may enable the cure of patients with primary bone marrow DLBCL.

\section{Case Report}

A 39-year-old woman suffering from dyspnea on exertion was admitted to our hospital. On physical examination, her body temperature was $37.0^{\circ} \mathrm{C}$, the conjunctiva was anemic, but neither lymphadenopathy nor hepatosplenomegaly was observed.

Laboratory findings showed a decreased white blood cell count of $2,950 \times 10^{6} / \mathrm{L}$, a low hemoglobin level of 


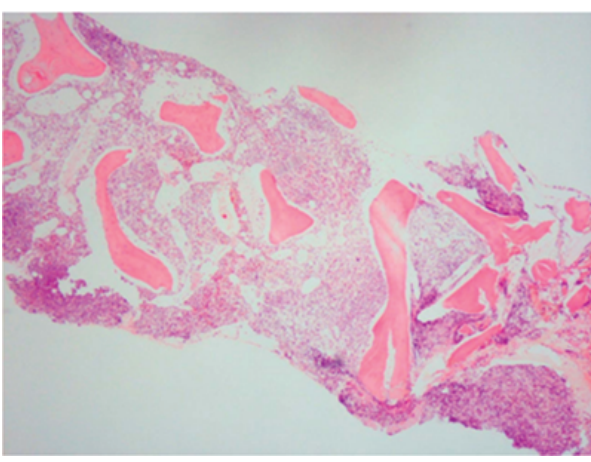

(a)

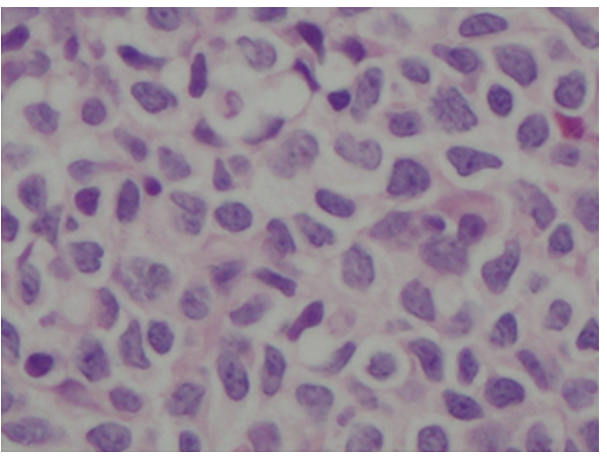

(b)

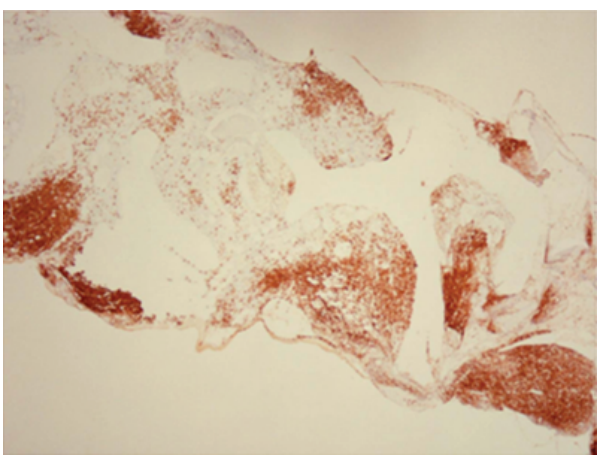

(c)

Figure 1: Images of the bone marrow biopsy showing the involvement of large abnormal lymphoid cells with focal clusters. (a) Hematoxylin-eosin staining, low-power field $(\times 40)$; (b) hematoxylin-eosin staining, high-power field $(\times 1,000)$; (c) the tumor cells were positive for CD20.

$6.5 \mathrm{~g} / \mathrm{dL}$, an increased soluble interleukin-2 receptor level of $3,350 \mathrm{U} / \mathrm{mL}$, and a normal serum lactate dehydrogenase level of $154 \mathrm{U} / \mathrm{L}$. Initial bone marrow aspiration revealed a dry tap, but bone marrow biopsy showed the involvement of large abnormal lymphoid cells with focal clusters (Figures 1(a) and $1(\mathrm{~b})$ ). Hemophagocytosis and sinusoidal involvement of lymphoma cells were absent.

Immunohistochemical studies indicated that the lymphoma cells were positive for CD20 (Figure 1(c)) and negative for CD3, CD5, CD34, MPO, TdT, cyclin D1, and Bcl2. Karyotypic analysis of a second bone marrow aspiration showed a complex chromosomal abnormality: 46, XX, add

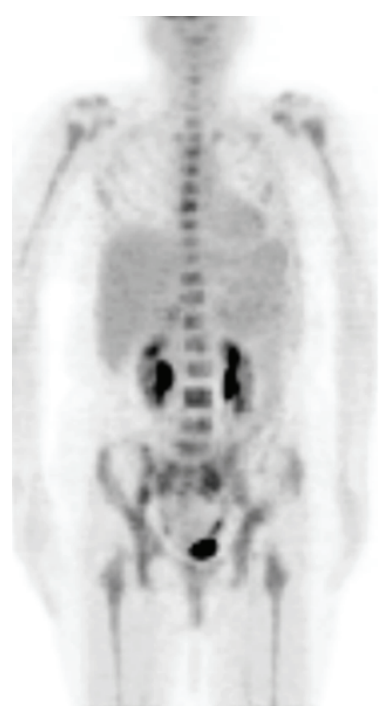

(a)

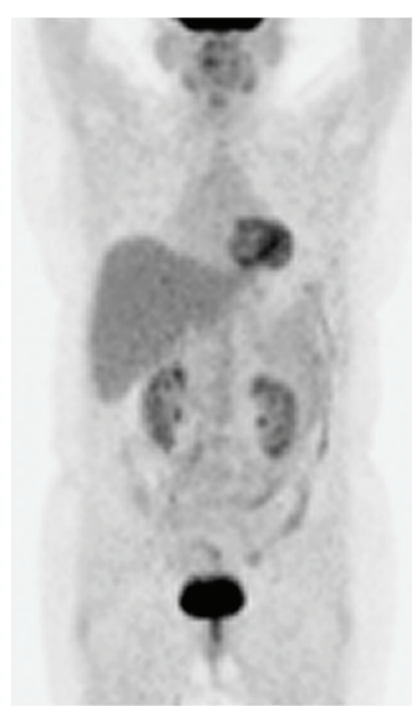

(b)
Figure 2: (a) An ${ }^{18} \mathrm{~F}$-fluorodeoxyglucose positron emission tomography (FDG-PET) scan showing disseminated bone marrow uptake at diagnosis. (b) FDG-PET scan after autologous stem cell transplantation showing the resolution of FDG uptake.

(10) (q22 or q23). An ${ }^{18} \mathrm{~F}$-fluorodeoxyglucose positron emission tomography scan revealed disseminated bone marrow uptake, but no abnormal uptake was observed at other sites (Figure 2(a)). These clinical findings led to a diagnosis of primary bone marrow DLBCL. The international prognostic index (IPI) score was 1.

R-CHOP (rituximab, cyclophosphamide, doxorubicin, vincristine, and prednisolone) was started, and bone marrow examination showed the disappearance of lymphoma cells after 6 courses of R-CHOP. Our patient received an additional 2 courses of R-CHOP, followed by stem cell mobilization chemotherapy consisting of $24 \mathrm{mg} /$ day dexamethasone (days 1 to 10 ), $60 \mathrm{mg} / \mathrm{m}^{2}$ carmustine (day 2), $75 \mathrm{mg} \cdot \mathrm{m}^{-2}$ day $^{-1}$ etoposide (days 4 to 7 ), $200 \mathrm{mg} \cdot \mathrm{m}^{-2}$ day $^{-1}$ cytarabine (days 4 to 7 ), $20 \mathrm{mg} / \mathrm{m}^{2}$ melphalan (day 3 ), and $375 \mathrm{mg} / \mathrm{m}^{2}$ rituximab (day 1 ), which was started 40 days after the completion of the last course of R-CHOP. Filgrastim at a dose of $600 \mu \mathrm{g}$ was administered on day 11 and continued until the completion of leukapheresis. Leukapheresis was performed using a continuous-flow blood cell separator (Cobe Spectra, Lakewood, CO, USA), and a total of $7.3 \times 10^{6} \mathrm{CD} 34^{+}$cells/kg body weight were obtained.

Two weeks after stem cell collection, our patient received a conditioning regimen of $300 \mathrm{mg} / \mathrm{m}^{2}$ carmustine (day -6), $100 \mathrm{mg} \cdot \mathrm{m}^{-2}$ day $^{-1}$ etoposide (days -5 to -2 ), $200 \mathrm{mg} \cdot \mathrm{m}^{-2}$ day $^{-1}$ cytarabine (days -5 to -2 ), $140 \mathrm{mg} / \mathrm{m}^{2}$ melphalan (day -1 ), and $375 \mathrm{mg} / \mathrm{m}^{2}$ rituximab (day -9 ), followed by autologous stem cell transplantation (ASCT). All of the collected stem cells were infused, and filgrastim was administered at a dose of $450 \mu \mathrm{g}$ on days +1 to +10 and at $150 \mu \mathrm{g}$ on days +11 to +13 . Engraftment of neutrophils $\left(\right.$ ANC $\left.>1 \times 10^{6} / \mathrm{L}\right)$ was performed on day +11 . Seven years 
have passed since the transplantation and the patient remains in remission (Figure 2(b)).

\section{Discussion}

Primary bone marrow DLBCL is a rare but distinctive entity of extranodal lymphoma with a poor prognosis.

Because primary bone marrow DLBCL is rare, no standard therapy has been established. Chang et al. reported 8 cases of primary bone marrow DLBCL [3]. Four patients were treated with chemotherapy alone, of which 3 died at 8,10 , and 22 months after the initial diagnosis. In contrast, of the 4 patients treated with chemotherapy combined with rituximab (R-CHOP, 3 patients; R-COP, 1 patient), 3 have remained in remission for 3,10 , and 14 months. These results suggest that similar to other types of DLBCL, chemotherapy combined with rituximab would be a standard strategy for primary bone marrow DLBCL too. However, the long-term outcome is unknown because the followup period is too short.

Although high-dose chemotherapy rescued by autograft is known to improve the outcome of relapsed lymphoma [5], the role of upfront ASCT for the patients with DLBCL is controversial $[8,9]$. Presently upfront ASCT is recommended only in selected high-risk circumstances or in the context of clinical trials [10]. Although primary bone marrow DLBCL is thought to be a type of high-risk lymphoma, the role of autologous hematopoietic stem cell transplantation is unclear because of its extremely rare incidence. To date, 3 cases of primary bone marrow DLBCL (including the present one) treated by autologous hematopoietic stem cell transplantation have been reported, all of which have remained in remission for 14 months, 12 months, and 7 years (our patient) after transplantation $[3,11]$.

In patients with primary bone marrow DLBCL, the high risk of lymphoma cells in the autograft being contaminated is a major problem because it may cause relapse. Therefore, an in vivo rituximab-purged autograft was used for transplantation in our patient. She has been alive without evidence of relapse for the past 7 years. This suggests that ASCT using an in vivo rituximab-purged autograft might be a promising strategy for the treatment of primary bone marrow DLBCL.

However, because this is only a case report, the role of ASCT in curing primary bone marrow DLBCL remains unclear. An accumulation of cases is required to clarify the role of ASCT with an in vivo rituximab-purged autograft for primary bone marrow DLBCL.

\section{References}

[1] K. F. Wong, J. K. C. Chan, C. S. Ng, Y. C. Chu, L. P. K. Li, and C. H. Chan, "Large cell lymphoma with initial presentation in the bone marrow," Hematological Oncology, vol. 10, no. 5, pp. 261-271, 1992.

[2] J. A. Strauchen, "Primary bone marrow B-cell lymphoma: report of four cases," Mount Sinai Journal of Medicine, vol. 70, no. 2, pp. 133-138, 2003.

[3] H. Chang, Y. S. Hung, T. L. Lin et al., "Primary bone marrow diffuse large B cell lymphoma: a case series and review," Annals of Hematology, vol. 90, no. 7, pp. 791-796, 2011.
[4] D. Kajiura, Y. Yamashita, and N. Mori, "Diffuse large B-cell lymphoma initially manifesting in the bone marrow," American Journal of Clinical Pathology, vol. 127, no. 5, pp. 762-769, 2007.

[5] T. Philip, C. Guglielmi, A. Hagenbeek et al., "Autologous bone marrow transplantation as compared with salvage chemotherapy in relapses of chemotherapy-sensitive non-Hodgkin's lymphoma," New England Journal of Medicine, vol. 333, no. 23, pp. 1540-1545, 1995.

[6] C. Haioun, E. Lepage, C. Gisselbrecht et al., "Survival benefit of high-dose therapy in poor-risk aggressive non-Hodgkin's lymphoma: final analysis of the prospective LNH87-2 protocol- a groupe d'etude des lymphomes de l'adulte study," Journal of Clinical Oncology, vol. 18, no. 16, pp. 3025-3030, 2000.

[7] T. Flohr, G. Hess, K. Kolbe et al., "Rituximab in vivo purging is safe and effective in combination with CD34-positive selected autologous stem cell transplantation for salvage therapy in BNHL," Bone Marrow Transplantation, vol. 29, no. 9, pp. 769$775,2002$.

[8] N. Schmitz, M. Nickelsen, M. Ziepert et al., "Conventional chemoimmunotherapy (R-CHOEP-14) or high-dose therapy (R-Mega-CHOEP) for young, high-risk patients with aggressive B-cell lymphoma: final results of the randomized Mega-CHOEP-trial of the German high-grade non-Hodgkin lymphoma study group (DSHNHL)," Annals of Oncology, vol. 22, supplement 4, abstract 073, 2011.

[9] U. Vitolo, A. Chiappella, E. Brusamolino et al., "A randomized multicentre phase III study for first line treatment of young patients with high risk (AAIPI 2-3) diffuse large B-cell lymphoma (DLBCL): rituximab (R) plus dose-dense chemotherapy $\mathrm{CHOP} 14 / \mathrm{MegaCHOP} 14$ with or without intensified high-dose chemotherapy (HDC) and autologous stem cell transplantation (ASCT). Results of DLCL04 trial of Italian Lymphoma Foundation (FIL)," Annals of Oncology, vol. 19, supplement 4, abstract 072, 2011.

[10] NCCN Clinical Practice Guideline in Oncology, Non-Hodgkin's Lymphomas version 3, 2012 http://www.nccn.org/professionals/physician_gls/pdf/nhl.pdf.

[11] M. Hishizawa, K. Okamoto, K. Chonabayashi, H. Kaneko, M. Watanabe, and M. Tsudo, "Primary large B-cell lymphoma of the bone marrow," British Journal of Haematology, vol. 136, no. 3, p. 351, 2007. 


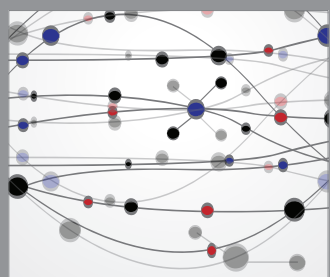

The Scientific World Journal
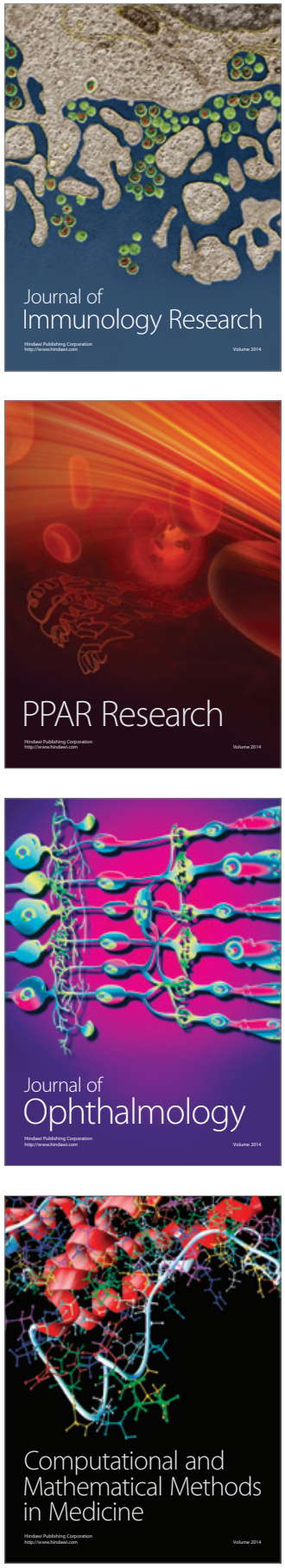

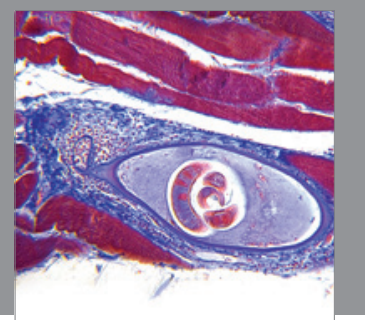

Gastroenterology

Research and Practice
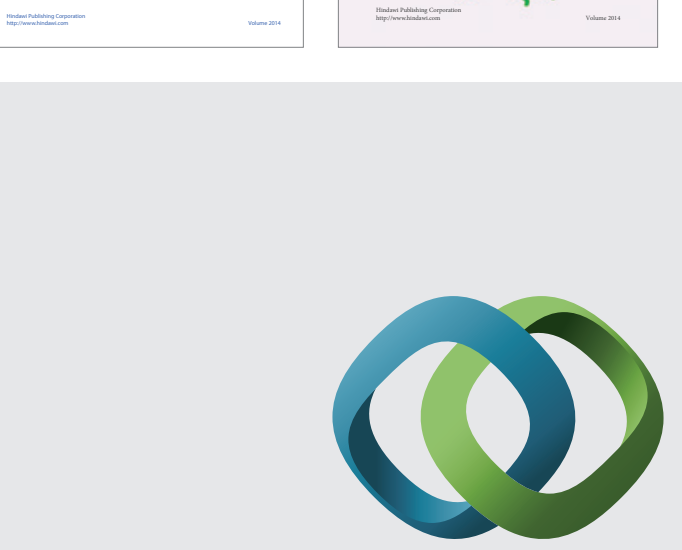

\section{Hindawi}

Submit your manuscripts at

http://www.hindawi.com
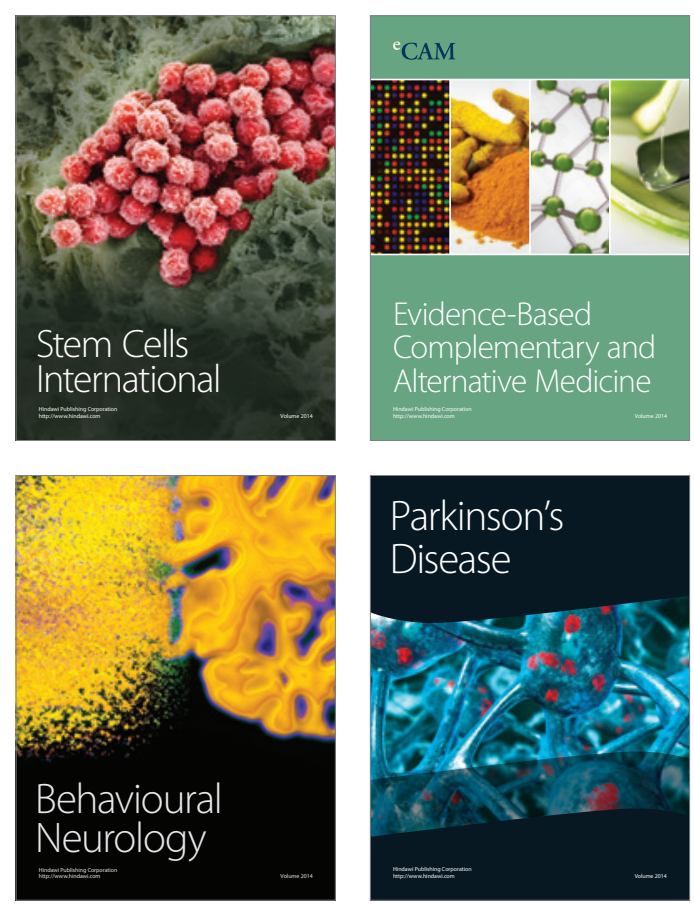

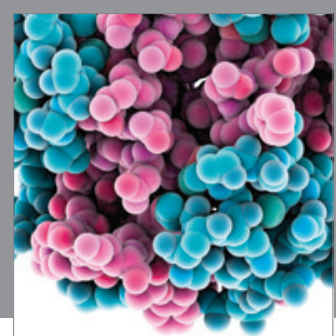

Journal of
Diabetes Research

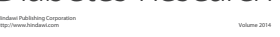

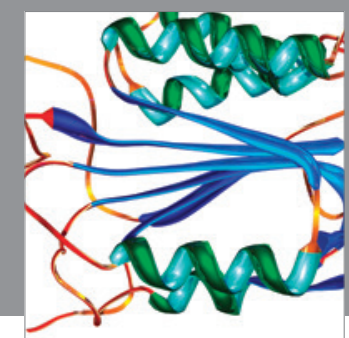

Disease Markers
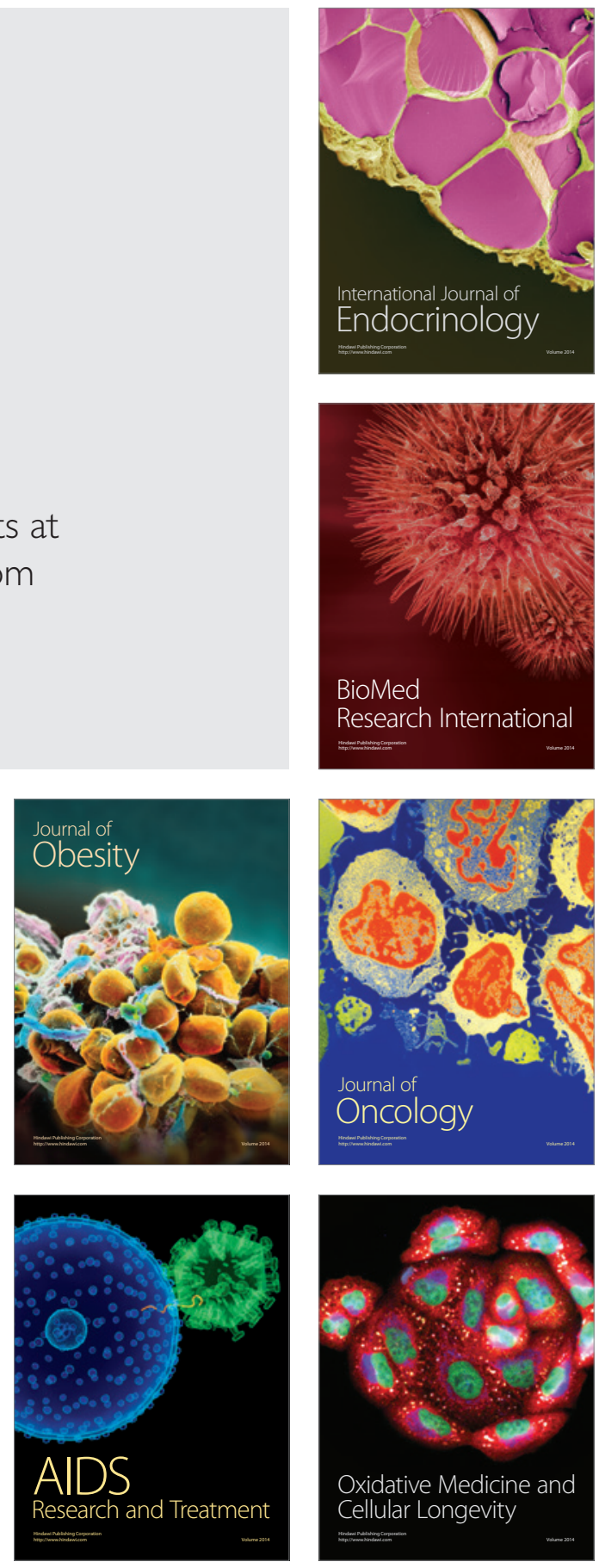